subjects there was an increase in bronchial hyperresponsiveness only during the first two weeks of the study, but by the end of four weeks this increase had disappeared. In the study of Vathenen et al (ref 7) with eight asthmatic subjects it was observed that a (rebound) increase in hyperresponsiveness occurred, not whilst using the $\beta$ agonist but afterwards. In our own study (ref 14) an increase in hyperresponsiveness was observed when using a $\beta$ agonist in a selected group of 15 patients. These 15 patients were selected on the condition that they had not used any $\beta$ agonists or $\beta$ blockers for one year before the start of the study. They were part of a much larger group of 144 patients who, on average, did not show an increase in bronchial hyperresponsiveness during the use of the $\beta$ agonist (ref 1 , not presented in the table). Looking at the presented table, it seems that the more patients involved in these studies the less clear is the adverse prognosis of bronchial hyperresponsiveness during the continuous use of a bronchodilator. This underlines our conclusion that only in subgroups of patients might the continuous use of a $\beta_{2}$ adrenergic drug have an adverse effect on bronchial hyperresponsiveness. The only exception seems to be the study of Sears and Taylor themselves (ref 3 ) with a relatively large number of 64 patients. However, this is the only study in which patients were allowed to use anti-inflammatory drugs as well as their bronchodilator drugs.

As Sears and Taylor have already acknowledged, the observed changes in hyperresponsiveness are small. They are all between 0.5 and 1.5 doubling doses of the challenge test, which is virtually similar to the repeatability of the challenge test ${ }^{1}$ and is therefore of doubtful clinical significance.

The purpose of writing our editorial was not to present a neutral position in this important issue but to show that the general fear that exists among doctors and patients about the chronic use of bronchodilators does not seem to be justified by the data available at this moment. We did not, and do not, doubt that bronchodilators probably have a (small) negative influence on the long term prognosis of bronchial hyperresponsiveness in certain groups of asthmatic patients. Subgroup analyses of our own data have shown that especially allergic hyperresponsive asthmatic patients seem to have an increased progression of asthma with continuous use of a $\beta$ agonist. ${ }^{2}$ Another important issue which still has to be settled is what additional bronchodilator drug should be used (and in what dose) when the patient receives a combination of an anti-inflammatory drug and a bronchodilator.

C P VAN SCHAYCK C L A VAN HERWAARDEN Departments of General Practice and Pulmonary Diseases, Nijmegen University, PO Box 9101 , 6500 HB Nijmegen, The Netherlands

1 Cockcroft DW, Killian DN, Mellon JJA, Hargreave FE. Bronchial rectivity to inhaled histamine: a method and clinical survey. Clin tallergy 1977;7:235-9.

2 Schayck CP van, Kraak A, Dompeling E, Folgering $\mathrm{H}$, Weel $\mathrm{C}$ van. Dose-response relationship between the decline in lung function and the daily dose of salbutamol and ipratropium
bromide. Am Rev Respir Dis 1992;145(Supp1 2):A61.

\section{Extrapulmonary effects of fenoterol and salbutamol in normal subjects}

Newnham et al have attempted the difficult task of trying to dissect relative $\beta_{1}$ and $\beta_{2}$ mediated cardiovascular responses to large doses of salbutamol and fenoterol in normal subjects with a low dose of atenolol (June 1993;48:656-8). There are two issues: firstly, the comparative responses to similar doses of these agents by inhalation and, secondly, their selectivity at the $\beta$ receptor.

Newnham et al showed that salbutamol and fenoterol in doses of $1 \mathrm{mg}$ and $3 \mathrm{mg}$ from metered dose inhalers led to similar increases in heart rate, stroke distance, and tremor, with fenoterol causing a slightly greater fall in serum potassium concentration and a greater rise in systolic blood pressure than salbutamol. Their findings suggest smaller differences between higher doses of salbutamol and fenoterol on extrapulmonary effects than other studies, whether the comparisons have been made in vitro, in vivo, or in different species. ${ }^{12}$ Invariably fenoterol has been found to be more potent in large doses than salbutamol. Studies using intravenous preparations have found a 2-4 times greater effect on heart rate with fenoterol, and this has led to a tenfold difference in the concentration of intravenous solutions used routinely $(500 \mu \mathrm{g} / \mathrm{ml}$ salbutamol compared with $50 \mu \mathrm{g} / \mathrm{ml}$ fenoterol). The reasons for the different findings of Newnham $e t$ al are unclear.

The attempts by the authors to dissect relative $\beta_{1}$ and $\beta_{2}$ effects have failed as they have shown that atenolol significantly attenuates the $\beta_{2}$ mediated effect on heart rate, tremor, and serum potassium concentration. Other designs based on studies by Wellstein et $a l^{3}$ or Hall et $a l^{4}$ may enable such relative $\beta$ receptor specificity to be shown.

J CRANE
C BURGESS
R BEASLEY
Department of Medicine,
Wellington School of Medicine,
Wellington,
New Zealand
C WONG
Department of Medicine,
University of Otago,
Dunedin,
New Zealand

1 Wong C, Pavord I, Williams J, Briton J, Tattersfield A. Bronchodilator, cardiovascular and hypokalaemic effects of fenoterol, salbutamol and terbutaline in asthma. Lancet 1990; 336:1396-9.

2 Burgess C. An overview of experimental methods. In: Beasley C, Pearce N, eds. The role of beta receptor agonist therapy in asthma role of beta receptor agonist therapy in asthma
mortality. Boca Raton: CRC Press, 1993:12748 .

3 Wellstein A, Belz G, Palm D. Beta adrenoceptor subtype binding activity in plasma and beta blockade by propanolol and beta-1 selective bisoprolol in humans. Evaluation with Schild plots. F Pharmacol Exp Ther 1988;246:328-37.

4 Hall J, Petch M, Brown M. Intracoronary injections of salbutamol demonstrate the presence of functional $\beta_{2}$ adrenoceptors in the human heart. Circ Res 1989;65:546-53.

AUTHORS' REPLY In reply to the letter of Crane et al there are some fundamental issues which, although discussed in the paper, require further clarification.

The purpose of our study was not to assess the relative potency of fenoterol and salbutamol, which requires dose-response curves in asthmatic subjects to ascertain relative bronchodilator and systemic $\beta_{2}$ receptor activity. The $25 \mathrm{mg}$ dose of atenolol in our study was chosen on the basis of it producing relatively selective $\beta_{1}$ blockade. It is, however, well documented that atenolol displays dose related $\beta_{2}$ blockade, ${ }^{12}$ and so it is not, perhaps, surprising that even a $25 \mathrm{mg}$ dose produced a degree of $\beta_{2}$ antagonism. The important point is that a comparable degree of attenuation occurred with heart rate and potassium responses, both of which have been shown to be $\beta_{2}$ mediated. ${ }^{1-3}$ Indeed, this occurred to the same extent with both fenoterol and salbutamol.

If fenoterol had stimulated cardiac $\beta_{1}$ receptors to a greater degree than salbutamol, one would have predicted atenolol to have antagonised the chronotropic response to fenoterol more than salbutamol. This was clearly not the case, with the percentage attenuation by atenolol at the $4 \mathrm{mg}$ dose being $14 \%$ for fenoterol and $16 \%$ for salbutamol. The percentage attenuation of the systolic blood pressure was also comparable for both fenoterol $(10 \%)$ and salbutamol $(8 \%)$. Thus, whilst fenoterol may exhibit greater $\beta_{2}$ potency, there is no evidence for it being less selective in terms of relative car$\operatorname{diac} \beta_{1} / \beta_{2}$ receptor stimulation. It is also worth pointing out that in a study from Windom et $a l^{4}$ in asthmatic subjects there was no difference in either chronotropic or systolic blood pressure responses to fenoterol and salbutamol, in contrast with isoprenaline which produced greater effects, presumably $\beta_{1}$ adrenoceptor mediated. ${ }^{5}$

Our in vivo data are indeed supported by in vitro data in human right atria, ${ }^{6}$ showing that the relative $\mathrm{pA}_{2}$ values for practolol $\left(\beta_{1}\right.$ antagonist) and ICI 18551 ( $\beta_{2}$ antagonist) were 5.47 and 8.24 respectively, for antagonism of the inotropic response to fenoterol. Taken together we believe that the body of evidence supports the hypothesis that the effects of fenoterol on the human heart are predominantly caused by stimulation of car$\operatorname{diac} \beta_{2}$ receptors.

B J LIPWORTH
D M NEWNHAM
D G MCDEVITT
Department of Clinical Pharmacology,
Ninewells Hospital and Medical School,
Dundee DD1 9SY

1 Lipworth BJ, Brown RA, McDevitt DG. Assessment of airways, tremor and chronotropic responses to inhaled salbutamol in the quantification of $\beta_{2}$ adrenoceptor blockade. Br f Clin Pharmacol 1989;28:95-102.

2 Lipworth BJ, McFarlane LC, Coutie WJ, McDevitt DG. Evaluation of metabolic responses to inhaled salbutamol in the measurement of $\beta_{2}$ adrenoceptor blockade. Eur $\mathcal{F}$ Clin Pharmacol 1989;37:297-300.

3 Hall JA, Petch MC, Brown MJ. Intracoronary injections of salbutamol demonstrate the presence of functional $\beta_{2}$ adrenoceptors in the human heart. Circ Res 1989;65:546-53.

4 Windom HH, Burgess CD, Siebers RWL, Purdie GP, Pearce N, Crane J, et al. The pulmonary and extrapulmonary effects of inhaled $\beta$-agonists in patients with asthma. Clin $\beta$-agonists in patients with as
Pharmacol Ther 1990;48:296-301.

5 Lipworth BJ, Tregaskis BF, McDevitt DG. Comparison of hypokalaemic, electrocardioComparison of hypokalaemic, electrocardio-
graphic and haemodynamic responses to graphic and haemodynamic responses to
inhaled isoprenaline and salbutamol in young inhaled isoprenaline and salbutamol in young and elderly subject

6 Wilson C, Lincoln C. $\beta$-adrenoceptor subtypes in human, rat, guinea-pig and rabbit atria. $\mathcal{J}$ Cardiovasc Pharmacol 1984;6:1216-21. 